\title{
Educação ambiental com atividades lúdicas no ensino infantil
}

\author{
Environmental education with ladical activities in children's education \\ Educación ambiental con actividades lúdicas en la enseñanza infantil \\ Valquiria Costa Marvila Silva ${ }^{1 *}$, Désirée Gonçalves Raggi².
}

\begin{abstract}
RESUMO
Objetivo: Neste artigo, pesquisou-se sobre a Educação Ambiental com atividades lúdicas no Ensino Infantil com intuito de investigar como a Educação ambiental com atividades lúdicas no ensino infantil contribuem para o desenvolvimento da consciência ambiental das crianças da Educação Infantil. Método: Para tal será realizado um estudo bibliográfico, sobre Educação Ambiental com atividades lúdicas na educação infantil, objeto deste estudo. Resultados: As atividades lúdicas constituem um recurso pedagógico eficaz, e contribui para o desenvolvimento da consciência ambiental das crianças da educação infantil, ensinando desde cedo a importância de preservar o meio ambiente, despertando autonomia, criticidade e responsabilidade. As atividades lúdicas tornaram mais facilmente assimiláveis as informações vivenciadas durante as práticas. Considerações finais: $O$ ensino de Educação Ambiental com atividades lúdicas em espaços educativos sustentáveis, visando a participação das crianças na Educação Infantil torna-se uma aprendizagem permanente e que tem o objetivo de estabelecer valores que contribuam para a transformação humana e social, acarretando mudanças de hábitos e de atitudes relacionados à preservação.
\end{abstract}

Palavras-chaves: Educação Ambiental, Educação Infantil, Atividades lúdicas.

\begin{abstract}
Objective: In this article, we investigated about Environmental Education with play activities in Child Education in order to investigate how Environmental Education with play activities in children's education contribute to the development of environmental awareness of children in Early Childhood Education. Method: To this end, a bibliographic study will be carried out on Environmental Education with play activities in early childhood education, object of this study. Results: Play activities are an effective pedagogical resource and contribute to the development of children's environmental awareness in early childhood education, teaching from an early age the importance of preserving the environment, awakening autonomy, criticality and responsibility. The play activities made it easier to assimilate the information experienced during the practices. Final considerations: The teaching of Environmental Education with play activities in sustainable educational spaces, aiming at the participation of children in Early Childhood Education becomes a permanent learning that aims to establish values that contribute to human and social transformation, leading to changes habits and attitudes related to preservation.
\end{abstract}

Keywords: Environmental Education, Child education, Play activities.

${ }^{1}$ Faculdade Vale do Cricaré. E-mail: valquiriamarvila@hotmail.com

${ }^{2}$ Universidad del Norte - Revalidado pela Universidade Federal de Pernambuco - UFPE.

SUBMETIDO EM: 3/2019

ACEITO EM: 4/2019

PUBLICADO EM: 7/2019

REAS/EJCH | Vol. Sup. 25 | e633 | DOI: https://doi.org/10.25248/reas.e633.2019 Página 1 de 7 


\section{RESUMEN}

Objetivo: En este artículo, se investigó sobre la Educación Ambiental con actividades lúdicas en la Enseñanza Infantil con el propósito de investigar cómo la Educación ambiental con actividades lúdicas en la enseñanza infantil contribuyen al desarrollo de la conciencia ambiental de los niños de Educación Infantil. Método: Para ello se realizará un estudio bibliográfico, sobre Educación Ambiental con actividades lúdicas en la educación infantil, objeto de este estudio. Resultados: Las actividades lúdicas constituyen un recurso pedagógico eficaz, y contribuye al desarrollo de la conciencia ambiental de los niños de la educación infantil, enseñando desde temprano la importancia de preservar el medio ambiente, despertando autonomía, criticidad y responsabilidad. Las actividades lúdicas hicieron más fácilmente asimilables las informaciones vivenciadas durante las prácticas. Consideraciones finales: La enseñanza de Educación Ambiental con actividades lúdicas en espacios educativos sostenibles, visando la participación de los niños en la Educación Infantil se convierte en un aprendizaje permanente y que tiene el objetivo de establecer valores que contribuyan a la transformación humana y social, acarreando cambios de hábitos y de actitudes relacionadas a la preservación

Palabras claves: Educación Ambiental, Educación Infantil, Actividades lúdicas.

\section{INTRODUÇÃO}

De acordo com Tristão MP (2004); A educação ambiental na educação infantil é um conceito que necessita ser trabalhado em conjunto com a sociedade. A escola é um ambiente propício para aprendizagem, por isso a educação infantil é de suma importância para introduzir a temática, pois desenvolvem-se competências e contribui para uma mudança de atitude e comportamento

É inquestionável a importância de se desenvolver conceitos de Educação Ambiental com atividades lúdicas na Educação Infantil, uma vez que a sociedade brasileira ainda não resolveu os problemas ambientais mais elementares, tais como, separação adequada do lixo, poluição de solos e água, desmatamentos, dentre outros Tristão MP (2005).

De acordo com a Política Nacional de Educação Ambiental - Lei oㅜ 9.795/1999, artigo 1ํ:

"Entendem-se por educação ambiental os processos por meio dos quais o individuo e a coletividade constroem valores sociais, conhecimentos, habilidades, atitudes $e$ competências voltadas para a conservação do meio ambiente, bem de uso comum do povo, essencial à sadia qualidade de vida e sua sustentabilidade".

Segundo Dewey J (1971); A promoção da Educação Ambiental nas escolas visa não somente conscientizar as crianças, mais que isso, é preciso que os educadores criem situações de aprendizagem que envolvam a comunidade escolar no sentido de pensar em propostas de intervenção na realidade, pois sem um trabalho coletivo e bem direcionado, as ações poderiam se perder ao longo do processo ensino aprendizagem. Como se tem observado, os projetos pontuais efetivados em datas comemorativas não apresentaram resultados efetivos

Diante desse contexto, o presente estudo busca trabalhar cuidados com o meio ambiente na educação Infantil, pois nesta etapa ocorrem as primeiras aprendizagens escolares, descobertas, experiências e 0 contato com a natureza de forma significativa, e surgem situações em que as crianças aprendem valores, atitudes, comportamentos e ideias que as tornarão indivíduos conscientes e sustentáveis.

Tem-se como objetivo investigar como a Educação Ambiental com atividades lúdicas contribuem para o desenvolvimento da consciência ambiental no ensino infantil.

De acordo Referencial Curricular Nacional para a Educação Infantil (RCNEI) esta fase de estudos:

"se constitui em um conjunto de fenômenos naturais e sociais indissociáveis diante do qual elas se mostram curiosas e investigativas. Desde muito pequenas, pela interação com o meio natural e social no qual vivem, as crianças aprendem sobre $o$ 
mundo, fazendo perguntas e procurando respostas às suas indagações e questões. Como integrantes de grupos socioculturais singulares, vivenciam experiências e interagem num contexto de conceitos, valores, ideias, objetos e representações sobre os mais diversos temas a que têm acesso na vida cotidiana, construindo um conjunto de conhecimentos sobre o mundo que as cerca". (Referencial Curricular Nacional para a Educação Infantil, BRASIL, 1998, v.3, p.163).

Pietrobon SRG (2017); ressalta que a educação Infantil se constitui na primeira etapa da educação básica e tem, entre outras, a função de promover o desenvolvimento integral da criança, em seus aspectos físico, psicológico, intelectual e social.

Como explicita a formação do sujeito-criança e sua compreensão e relação com as diferentes áreas do conhecimento ficará prescindirá de uma proposta pedagógica que assuma a criança como sujeito de direitos e cidadã e que a considere um ser que pensa, age, reflete. Logo essa fase é um momento profícuo para aludir o conceito de preservação é promover a capacidade de torná-la agente transformador consciente de seu próprio ambiente. De acordo com os objetivos gerais da RCNEI a criança deve: "Observar e explorar o ambiente com atitude de curiosidade, percebendo-se cada vez mais como integrante, dependente e agente transformador do meio ambiente e valorizando atitudes que contribuam para sua conservação" (BRASIL, 1998, vol. 1, p.63).

Para Maluf ACM (2012); O professor tem a função de desenvolver a consciência crítica de seus alunos. Portanto, é de suma importância que inclua em suas atividades rotineiras as experiências de mundo, incluindo gradualmente novas informações com o objetivo de aumentar seus saberes, estimulando a capacidade e a boa moral.

Tem-se como objetivo: Investigar como à Educação ambiental com atividades lúdicas no ensino infantil contribuem para o desenvolvimento da consciência ambiental das crianças da Educação Infantil.

Nesse contexto, foi formulada a problemática deste estudo: Como a Educação ambiental com atividades lúdicas no ensino infantil pode contribuir para o desenvolvimento da consciência ambiental das crianças da educação infantil?

\section{MÉTODOS}

Para tal foi realizado um estudo bibliográfico, sobre Educação Ambiental com atividades lúdicas na educação infantil, objeto deste estudo, buscou-se primordialmente a pesquisa em meios eletrônicos, gratuitos e de acesso público para análise de fontes secundárias tais como livros didáticos, guias e manuais com a temática em questão. Esta etapa possibilitou a construção da base necessária para um entendimento sobre a Educação Ambiental com atividades lúdicas no ensino infantil, estudos dirigidos ao objetivo deste artigo, que é identificar o tema central do estudo, declarar as principais conclusões relacionadas a esse tema.

A busca de materiais e o acesso ocorreu entre novembro e dezembro. Os descritores utilizados foram: Educação ambiental e educação infantil, O lúdico na Educação Infantil.

Os parâmetros referidos tiveram como objetivo propiciar uma melhor clareza sobre os direcionamentos apresentados em cada categoria de análise.

\section{RESULTADOS E DISCUSSÃO}

A pesquisa proporcionou instigar a conscientização e a sensibilização de cada criança na Educação Infantil acerca da educação ambiental por meio da inserção de atividades lúdicas, ensinando desde cedo a importância de preservar o meio ambiente, despertando autonomia, criticidade e responsabilidade.

Melhor do que folhear livros com desenhos e figuras de paisagens e animais, essa metodologia leva a criança a conhecer concretamente o mundo e a refletir sobre o meio ambiente, de forma lúdica e prazerosa conforme sugestiona Tristão MP (2005). 


\section{Educação ambiental e educação infantil}

De acordo com Maluf ACM (2008); A Educação Ambiental no Ensino Infantil exige um trabalho diferenciado e direcionado por meio de atividades lúdicas, pois a criança aprende a preservar o meio ambiente de forma prazerosa. As atividades lúdicas proporcionam às crianças uma aprendizagem de maneira agradável, especialmente, tendo em vista que envolvem diversos temas e possibilitam que a criança construa conhecimentos de forma divertida e abrangente, e permite que ela adquira autonomia e criatividade, aprendendo com os próprios erros e acertos. O exercício de atividades lúdicas é essencial no processo de desenvolvimento da criança, pois o mesmo desenvolve a imaginação e o aprendizado de novos conhecimentos e ocorre de forma divertida e natural.

Para Tristão MP (2004); a Educação Ambiental na Educação Infantil é uma temática que precisa ser trabalhada no coletivo escolar, envolvendo outros personagens, tais como, funcionários, gestores, pedagogos e familiares. A escola é um dos mais importantes espaços para semear atitudes, valores e respeito à natureza $\mathrm{e}$ isso deve ser preferencialmente efetivado desde a mais tenra idade, por isso a Educação Infantil se configura num momento de suma importância para introduzir a temática, já que nessa etapa de ensino as crianças em situações criativas e novas, interrogam, gostam de perguntar.

De acordo com VygotskyLS (2001) o processo de desenvolvimento e comportamento está associado diretamente à relação entre o organismo e o meio, sendo perpassado pela emoção. As emoções agem como reguladores internos do comportamento, quando são associadas aos estímulos externos, que podem levar as pessoas a demonstrar, ou não, emoções. Além do aspecto emocional é possível observar também a importância do uso da imaginação. Segundo Tristão MP (2007); a inserção da Educação Ambiental nas escolas visa não somente conscientizar as crianças, mais que isso, é preciso que os educadores criem situações de aprendizagem que envolvam a comunidade escolar no sentido de pensar em propostas de intervenção na realidade, pois sem um trabalho coletivo e bem direcionado, as ações poderiam se perder ao longo do processo de ensino-aprendizagem.

\section{O lúdico na Educação Infantil}

A inclusão da Educação Infantil na Base Nacional Comum Curricular (BNCC), para Oliveira Z (2012), representa um grande passo no processo de integração ao conjunto da Educação Básica, pois, segundo esta autora, a Educação Infantil tem uma história de luta social para se fazer respeitada, política e eticamente. Nesse sentido, estão expressas na BNCC (2017), orientações sobre as práticas pedagógicas realizadas em creches e pré-escolas, já que:

"[...] as creches e pré-escolas, ao acolher as vivências e os conhecimentos construídos pelas crianças no ambiente da família e no contexto de sua comunidade, e articulá-los em suas propostas pedagógicas, tem por objetivo de ampliar o universo de experiências, conhecimentos e habilidades dessas crinas, diversificando e consolidando novas aprendizagens, atuando de maneira complementar à educação familiar especialmente quando se trata da educação dos bebês e crianças pequenas, que envolve aprendizagens muito próximas aos dois contextos (familiar e escolar), como a socialização, a autonomia e a comunicação" (BRASIL, 2017, p. 32).

Nessa direção, a BNCC (2017), estabelece os 'Eixos Estruturantes das Práticas Pedagógicas, que são Interações e Brincadeiras', considera-os como experiências por meio das quais as crianças podem construir e apropriar-se de conhecimentos por meio de suas ações e interações com seus pares e com os outros, 0 que possibilita aprendizagens, desenvolvimento e socialização.

Observou-se também que a base estabelece o currículo para a Educação Infantil e o concebe como:

[...] um conjunto de práticas que buscam articular as experiências e os saberes das crianças com os conhecimentos que fazem parte do patrimônio cultural, artístico, científico e tecnológico, na convivência que as crianças estabelecem com professores e outras crianças (BRASIL, 2017, p. 39). 
Assim, quando se asseguram as interações e brincadeiras como eixos que devem ser respeitados, se faz necessário pensar sobre alguns conceitos no sentido de evitar equívocos relacionados ao tratamento didático dos conteúdos na Educação Infantil garantindo o direto das crianças aprenderem num espaço de interações e brincadeiras. E, nesse sentido, pode-se reportar ao grande educador FREIRE P (1989), que relata uma escola séria sem ser sisuda.

Mais uma vez, visando nortear os aportes teóricos que sustentam esta pesquisa, tomou-se como bússola o documento BNCC para construir uma análise que assume as brincadeiras e interações para se pensar na Educação Ambiental (EA), especialmente, levando-se em consideração que:

[...] a interação durante o brincar caracteriza o cotidiano da infância, trazendo muitas aprendizagens e potenciais para o desenvolvimento integral das crianças. Ao observar as interações e brincadeiras entre as crianças e delas com os adultos, é possível identificar, por exemplo, a expressão dos afetos, a mediação das frustações, e a resolução de conflitos e a regulação das emoções. Tendo em vista, os eixos estruturantes das práticas pedagógicas e as competências gerais da Educação Básica propostas pelo BNCC, e os seis direitos de aprendizagem e desenvolvimento: conviver, brincar, participar, explorar, expressar e conhecer-se", que devem estar assegurado e nortear o processo de aprendizagens das crianças no espaço infantil (BRASIL, 2017, p. 38).

BNCC (2017), evidenciou-se que as crianças vão percebendo que para viver com os próprios pares precisam ceder, respeitar, concordar etc. Deste modo, são nas relações sociais (na escola e fora dela) que as crianças se apropriam desse mundo exterior e são características, hábitos, atitudes do mundo externo, que num processo natural vivido vai se transformando em um mundo interno. É o que explica Bock AMMB (2002, p. 91), ao afirmar que é por meio "da mediação das relações sociais e das atividades que desenvolve, que o homem se individualiza, torna-se homem, desenvolve suas potencialidades e significa o mundo".

Essas orientações norteiam os educadores quanto aos caminhos didáticos que vão (re)ssignificar o processo de ensino dos conteúdos, ou seja, às crianças é garantido o direito de apropriar-se de forma crítica dos conteúdos. Portanto, ao professor está dada à responsabilidade de definir e praticar o melhor tratamento didático. A pesquisa proporcionou instigar a Educação ambiental com atividades lúdicas no ensino infantil. As atividades lúdicas constituem num recurso pedagógico eficaz, e contribui para o desenvolvimento da consciência ambiental das crianças da educação infantil, ensinando desde cedo a importância de preservar o meio ambiente, despertando autonomia, criticidade e responsabilidade.

As atividades lúdicas tornaram mais facilmente assimiláveis as informações vivenciadas durante as práticas fato que confirma a opinião de Negrine ACM (1994); Ainda de acordo com autor a atividade lúdica é de grande relevância na construção do desenvolvimento infantil, já que é por meio das atividades lúdicas a criança se desenvolve cognitivamente progride no raciocínio, desenvolve o pensamento e interage socialmente, compreende o ambiente que está inserido, satisfaz seus desejos e desenvolve suas habilidades e criatividade. Mais uma vez, visando nortear os aportes teóricos que sustentam esta pesquisa, tomou-se como bússola o documento BNCC para construir uma análise que assume as brincadeiras e interações para se pensar na EA, especialmente, levando-se em consideração que

[...] "a interação durante o brincar caracteriza o cotidiano da infância, trazendo muitas aprendizagens e potenciais para o desenvolvimento integral das crianças. Ao observar as interações e brincadeiras entre as crianças e delas com os adultos, é possível identificar, por exemplo, a expressão dos afetos, a mediação das frustações, e a resolução de conflitos e a regulação das emoções. Tendo em vista, os eixos estruturantes das práticas pedagógicas e as competências gerais da Educação Básica propostas pelo BNCC, e os seis direitos de aprendizagem e desenvolvimento: conviver, brincar, participar, explorar, expressar e conhecer-se", que devem estar 
assegurado e nortear o processo de aprendizagens das crianças no espaço infantil" (BRASIL, 2017, p. 38).

A Educação Infantil como etapa inicial da Educação Básica é de extrema importância para o desenvolvimento das habilidades que possibilitarão a compreensão e interiorização do mundo humano pela criança. Neste sentido, é essencial trabalhar atividades em que as crianças manipulem objetos, já que é a partir da interação com o meio, determinado por um ato intencional e dirigido do professor, que a criança aprende (VYGOTSKY LS 1998).

Conforme discorre Santos S MP (2000), as atividades lúdicas devem ocorrer de maneira de sejam capazes de gerar situações estimuladoras e eficazes para que assim aconteçam de fato as aprendizagens significativas. Por conseguinte, cientes de que as crianças vão desenvolver variadas habilidades durante toda a infância e que elas serão aperfeiçoadas ao longo do tempo, ao planejar as estratégias de ensino, os educadores devem escolher as melhores formas de oportunizar situações de aprendizagens diferenciadas, e as atividades lúdicas já demonstraram se encaixar perfeitamente nesse quesito.

Vygotsky LS (1998), também ressalta que as crianças aprendem interagindo com as outras crianças, em situações naturais de aprendizado como nas brincadeiras, mostrando mais uma vez o quanto o uso da ludicidade poderá ser importante no trabalho de desenvolvimento dos alunos. Para esse autor, a interação com o outro forma uma grande fonte de aprendizagem para as crianças, interação essa muito praticada quando a questão é o lúdico na sala de aula.

Maria Montessori M $(1949,1965)$ desenvolveu uma pedagogia científica que apontava o lúdico, bem como a brincadeira, como uma rica oportunidade para ajudar as crianças na aprendizagem. O pilar que sustenta a proposta de Montessori M $(1949,1965)$ reside no fato de desenvolver a autonomia das crianças com responsabilidade, com a autoeducação. A sala de aula não é qualquer lugar, é um espaço ordenado. Aprender é uma empreitada que deve se realizar de forma feliz e não dolorosa. Nesse sentindo compreendeu-se que o objetivo da educação de Montessori M $(1949,1965)$, como sendo uma educação para a vida, focaliza a autonomia como algo primordial para o desenvolvimento humano. Torna-se evidente a afirmação de que as crianças aprendem em um ambiente prazeroso.

\section{CONSIDERAÇÕES FINAIS}

Ao final deste estudo sobre a Educação Ambiental com atividades lúdicas foi possível concluir que a Educação Ambiental faz parte de um sistema educativo muito complexo e, por isto, é necessário que haja diferentes formas de incluir a temática ambiental nos currículos escolares, introduzindo mais criatividade e abandonando os modelos tradicionais. Diante disso, a EA expande um amplo espaço para repensar práticas pedagógicas e sociais, de forma que o professor é o mediador para que o aluno compreenda a interdependência dos problemas e das soluções ambientais, a importância da ação para a construção de uma sociedade mais sustentável.

Vale ressaltar o quão relevante é realizar o ensino de Educação Ambiental com atividades lúdicas em espaços educativos sustentáveis, visando a participação das crianças na Educação Infantil. Se tornando uma aprendizagem permanente e que tem o objetivo de estabelecer valores que contribuam para a transformação humana e social, acarretando mudanças de hábitos e de atitudes relacionados à preservação. Perante todo o conteúdo pesquisado e exposto, foi possível ressaltar que se trata de um processo progressivo e contínuo, que visa desenvolver cidadãos conscientes para resolver os problemas com o meio ambiente, fundamentado no entendimento das relações entre o homem e a natureza e, assim, desenvolvendo a capacidade para solucionar os problemas ambientais. É importante perceber a criança como um ser em desenvolvimento, com vontades e decisões próprias, cujos conhecimentos, habilidades e atitudes são adquiridos em função de suas experiências, em contato com o meio, e por meio de uma participação ativa na resolução de problemas e dificuldades. Dessa forma, ao desenvolver um projeto de trabalho, os educadores devem estar cientes de que algumas etapas devem ser seguidas. se apresentam aqui, algumas sugestões de ensino de Educação Ambiental atividades lúdicas como: roda de conversa, história infantil, mala viajante, passeio pela comunidade 
e pela praia, confecção das lixeiras, plantio de árvores e confecção de brinquedos com materiais recicláveis. Com isso, a escola cria possibilidades de formar cidadãos autônomos e participativos na sociedade.

\section{REFERÊNCIAS}

1. BOCK AMMB. (ORG). Psicologias: introdução ao estudo de psicologia. 13.ed. refor. e ampl. São Paulo. Saraiva, 2002.

2. BRASIL. Base Nacional Comum Curricular (BNCC). Educação é a Base. Brasília, MEC/CONSED/UNDIME, 2017.

3. BRASIL. Lei n. 9795 - 27 de abril de 1999. Dispõe sobre a Educação Ambiental. Política Nacional de Educação Ambiental. Brasília, 1999.

4. BRASIL. Ministério da Educação e do Desporto. Referencial Curricular Nacional para a Educação Infantil. Brasília: MEC/SEF, 1998.

5. DEWEY J. Experiência e educação. São Paulo: Nacional, 1971.

6. FREIRE P. A importância do ato de ler: em três artigos que se complementam. 23.ed. São Paulo. Autores associados: Cortez, 1989.

7. MALUF ACM. Atividades recreativas para divertir e ensinar. 4.ed. Petrópolis, RJ: Vozes: 2008.

8. MALUF, ACM. Atividades lúdicas para educação infantil: conceitos, orientações e práticas. $3^{a}$ edição. Petrópolis, RJ: Editora Vozes, 2012.

9. MONTESSORI M. Mente absorvente. Tradução de Pedro da Silveira. 2. ed. Portugal: Portugália, 1949.

10. 10.MONTESSORI M. Pedagogia científica: a descoberta da criança. Tradução de Aury Azélio Brunetti. São Paulo: Flamboyant, 1965.

11. NEGRINE A. Aprendizagem e desenvolvimento infantil. Porto Alegre: Propil, 1994.

12. 12.OLIVEIRA Z. Educação Infantil: fundamentos e métodos. São Paulo: 2012

13. 13.PIETROBON SRG. Fundamentos da educação infantil. Guarapuava: Ed. da Unicentro, 2010.

14. PIETROBON SRG. (orgs.). Práxis educativa e infância: intersecções para a formação integral da criança. Curitiba: CRV, 2017.

15. 15.SANTOS SMP. Brinquedoteca: a criança, o adulto e o lúdico. Petrópolis. Vozes.2000.

16. 16.VIGOTSKY LS. Psicologia pedagógica. São Paulo: Martins Fontes, 2001.

17. 17.VYGOTSKY LS. Formação social da mente. São Paulo; Martins Fontes, 1989.

18. TRISTÃO MA. educação ambiental e os contextos formativos na transição de paradigmas. In: Reunião anual da Anped, 30, 2007, Caxambu. Anais. Caxambu: ANPEd, 2007

19. TRISTÃO MA Educação Ambiental na formação de professores: redes de saberes. São Paulo: Annablume, 2004. $236 \mathrm{p}$.

20. TRISTÃO MP. Tecendo os fios da educação ambiental: o subjetivo e o coletivo, o pensado e 0 vivido. Universidade Federal do Espírito Santo, 2005. 